\title{
Hypernatremia in Newborn Due to Uncontrolled Maternal Diabetes Insipidus
}

\author{
Kyungmi Lee, $\mathrm{MD}^{1}$, Eun Sun Kim, MD, $\mathrm{PhD}^{1,2}$, and Kee Hyun Cho, $\mathrm{MD}^{1}$ \\ ${ }^{1}$ Department of Pediatrics, Kangwon National University Hospital, Chuncheon, Korea \\ ${ }^{2}$ Department of Pediatrics, Kangwon National University School of Medicine, Chuncheon, Korea
}

\section{ABSTRACT}

Neonatal hypernatremia often occurs in poorly breastfeeding infants, and rehydration without complications is the primary treatment. However, the etiologies and management for neonates who present with hypernatremia immediately after birth are not well reported. In this case report, we describe a neonate with hypernatremia and hyperosmolality, born to a mother with oligohydramnios of unknown etiology. Meticulous fluid therapies considering the time to physiologic diuresis were successfully performed, and the underlying cause was determined to be an uncontrolled maternal central diabetes insipidus.

Key Words: Hypernatremia; Infant, newborn; Diabetes insipidus; Oligohydramnios

\section{INTRODUCTION}

Neonatal hyponatremia often occurs in breastfeeding infants with insufficient feeding ${ }^{1)}$. Significant weight loss and dehydration are the common presenting symptoms; thus, an appropriate restoration of free water is vital in neonatal hypernatremia management to prevent morbidity or mortality ${ }^{2,3)}$.

However, when a newborn presents with significant hypernatremia immediately after birth, the degree of dehydration is difficult to evaluate. Further, the etiology and management of neonatal hypernatremia are not elucidated in previous literature. In this case report, we suggest a rare etiology of newborn hypernatremia and its management.

\section{CASE REPORT}

A female Korean infant was born at $36^{+6}$ weeks of gestation by emergency cesarean section to a 28-year-old primigravida due to preterm labor and maternal vaginal bleeding. The infant's birth weight was 2,250 g, and her Apgar scores were 7 and 9 at 1 and 5 minutes, respectively. Due to the unknown etiology of maternal oligohydramnios (nearly zero) without
Received: 11 August 2021

Revised: 13 September 2021

Accepted: 17 September 2021

Correspondence to: Eun Sun Kim, MD, PhD

Department of Pediatrics, Kangwon National University Hospital, Kangwon National University School of Medi cine, 156 Baengnyeong-ro, Chuncheon 24289, Korea

Tel: +82-33-258-2017

E-mail: naivesun1@hanmail.net

Copyright(c)

By Korean Society of Neonatology.

All right reserved.

This is an Open-Access article distributed under the terms of the Creative Commons At tribution Non-Commercial License (http:// creativecommons.org/licenses/by-nc/4.0), which permits unrestricted non-commercial use, distribution, and reproduction in any medium, provided the original work is properly cited. 
obvious rupture of membranes and unexpected intrauterine growth restriction, the infant was admitted to the neonatal inten sive care unit for monitoring.

The weight and head circumference at birth $(2,250 \mathrm{~g}$ and $31 \mathrm{~cm}$, respectively) were at the 10th percentile for gestational age, and the length at birth $(46 \mathrm{~cm})$ was adequate for gestational age. On physical examination, the infant's skin had decreased turgor and some wrinkles on the extremities, without facial dysmorphism or gross anomalies, and her abdomen was scaphoid with audible bowel sounds (Figure 1). Neurological examination findings were unremarkable.

Antenatal check-ups were performed by a local obstetrician. The parents reported no significant medical history for the mother, except for gastroenteritis symptoms (i.e., vomiting, diarrhea, and mild fever) 10 days prior to delivery, which was managed with intravenous fluid therapy for 2 days. The parents further revealed that all prenatal screening tests were normal, but the amniotic fluid volume was lower than normal since the second trimester. The mother appeared skinny; she reported that her pre-pregnancy weight was $54 \mathrm{~kg}$, which dropped to $51 \mathrm{~kg}$ (body mass index, 18.5 $\mathrm{kg} / \mathrm{m}^{2}$ ) prior to delivery, possibly due to frequent emesis starting from early pregnancy. She denied taking specific medications during pregnancy.

The infant's initial blood glucose level was $69 \mathrm{mg} / \mathrm{dL}$, and the blood gas analysis was normal. However, the initial laboratory tests revealed hypernatremia and polycythemia, with values as follows: plasma sodium (Na), $168 \mathrm{mEq} / \mathrm{L}$; potassium, $4.3 \mathrm{mEq} / \mathrm{L}$;

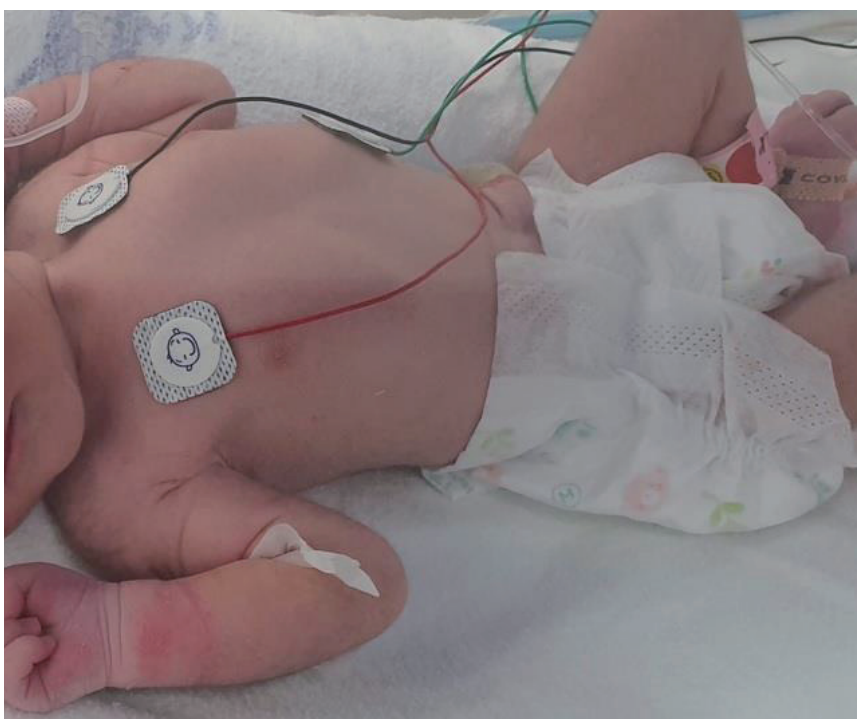

Figure 1. Immediately after birth, the infant was shown to have decreased skin turgor and wrinkles on the extremities. Her abdomen was scaphoid with audible bowel sounds. chloride, $128 \mathrm{mEq} / \mathrm{L}$; uric acid, $11.7 \mathrm{mg} / \mathrm{dL}$; blood urea nitrogen, $13.3 \mathrm{mg} / \mathrm{dL}$; creatinine (Cr), $1.2 \mathrm{mg} / \mathrm{dL}$; hematocrit, $65.1 \%$; white blood cell count, 8,800/ $\mu \mathrm{L}$; and platelet $189,000 / \mu \mathrm{L}$. Minimal enteral feeding (10 cc/3 hours, $35 \mathrm{cc} / \mathrm{kg} /$ day) was started. Initial bolus solutions were not administered as there were no signs of hemodynamic compromise. The free water deficit was calculated as follows: $[0.8 \times 2.25(\mathrm{~kg}) \times(168 / 145-1)=0.286(\mathrm{~L})]$. Thus, approxi mately $286 \mathrm{cc}$ of free water replacement over 48 hours was re quired for hypernatremia correction, totaling nearly $65 \mathrm{cc} / \mathrm{kg} /$ day. Normal saline $(0.9 \%)$ with $5 \%$ dextrose intravenous infusion was administered. Based on the history of oligohydramnios with a probability of renal failure, we adjusted the total input as maintenance $(70 \mathrm{cc} / \mathrm{kg} /$ day) and approximately $30 \%$ of correction volume (20 cc/kg/day) (Figure 2).

The first urine, which was only $4 \mathrm{cc}$, passed 7 hours after birth. At 12 hours after birth, $0.9 \%$ normal saline bolus was administered, and $0.45 \%$ normal saline with $5 \%$ dextrose intravenous infusion was started by replacing the free water deficit $(140 \mathrm{cc} / \mathrm{kg} /$ day in total, $70 \mathrm{cc} / \mathrm{kg} /$ day each for maintenance and replacement). Upon confirming the rate of $\mathrm{Na}$ correction ( $7 \mathrm{mEq} / \mathrm{L}$ in 15 hours) at 27 hours after birth, we adjusted the free water deficit volume and decreased the amount of intravenous fluid. At 36 hours, urine output had increased and fractional $\mathrm{Na}$ excretion was calculated as 0.36 (urine $\mathrm{Na}, 63 \mathrm{mEq} / \mathrm{L}$; plasma Cr, $1.0 \mathrm{mg} / \mathrm{dL}$; urine $\mathrm{Cr}, 112.2 \mathrm{mg} / \mathrm{dL}$; plasma Na, $156 \mathrm{mEq} / \mathrm{L}$ ). At 3-day, urine output had normalized, and enteral feeding volume started to increase. Within 4 days, the infant had gained $17.3 \%$ more weight from the recorded birth weight (from 2,250 to 2,640 g), and she did not show any respiratory or neurologic symptoms (Figure 2). Abdominal and brain ultrasonography findings were normal, and brain magnetic resonance imaging (MRI) showed no abnormalities. She was discharged on her 12th day of life, with normal electrolyte and hemoglobin levels and normal urination.

Acute maternal history was vital in determining the cause of hypernatremic dehydration in this infant. Her initial plasma $\mathrm{Na}$ level was $166 \mathrm{mEq} / \mathrm{L}$, and she had polydipsia (approximately $2 \mathrm{~L}$ of extra water intake) and polyuria. Due to maternal status, gestational diabetes insipidus (DI), a rare complication of pregnancy, was initially suspected. After several counseling sessions with the medical staff, the mother explained that she had undergone transsphenoidal pituitary adenoma resection 6 years prior and had this pregnancy by in vitro fertilization and embryo transfer. To rule out any hemorrhage or infarct in the pituitary lesion, brain MRI was performed, which revealed a small, residual pituitary 
gland with scar change and no other lesion. Finally, the mother was diagnosed with central DI after a water deprivation test and was started on oral desmopressin medication.

\section{DISCUSSION}

Breastfeeding-associated conditions are often reported when newborns show hypernatremic dehydration ${ }^{1)}$, and devastating conditions, such as cerebral hemorrhage, are a matter of concern. However, when a newborn presents with hypernatremia and hyperosmolality immediately after birth, maternal hypernatremia and hyperosmolality could be inferred as fluid balance in the fetus is dependent on the mother, and the fetal plasma osmolality moves in parallel with maternal plasma osmolality if the placenta functions normally ${ }^{4}$. The placenta has both an active and passive mechanism for Na transfer from mother to fetus using water as the osmotic gradient; therefore, maternal and fetal Na concentrations are similar ${ }^{5)}$. Oligohydramnios since the second trimester raises a concern of abnormal kidney function in the fetus since fetal urination mainly participates in amniotic fluid production starting the second trimester. In this case, fortunately, no renal anomalies were found, and urination had normalized. Considering the physiological amniotic fluid elimination process, ma ternal hyperosmolality and dehydration may cause oligohydramnios via fluid bulk flow in the chorionic plate by hydrostatic and oncotic pressure $^{6)}$.

Hypernatremia management depends on the etiology of hypernatremia, such as free water loss, high salt intake, or a mixed condition $^{2,3)}$.We calculated the free water loss from the plasma Na level, assuming that total body water was $80 \%$ in a near-term newborn, which was replaced initially by $0.9 \%$ normal saline and further restored by $0.45 \%$ saline to avoid cerebral edema from correcting the Na level by $>10 \mathrm{mEq} / \mathrm{L} / 12$ hours. Despite no evidence of renal ischemia or injury on ultrasonography, oliguria until 36 hours after birth complicated the treatment planning regarding further fluid therapy. Even without significant acute renal failure, the normal physiologic transition to the diuretic phase might be delayed in this patient ${ }^{7}$. With this complex condition, fluid the rapy needs to be changed according to varying plasma Na levels and onset of diuresis. On the 4 th day of life, the infant gained $390 \mathrm{~g}$ of body weight $(17.3 \%$, 2,640 g total, 36th percentile for gestational age) with diuresis and a near-normal Na level. Retrospectively, if we consider the patient dehydrated at birth, her birth weight can otherwise be appropriate for gestational age, with $14.8 \%$ of the weight loss being due to free water loss in utero.

In this case, the mother was diagnosed with central DI. DI can either be central or renal, and in pregnancy, transient gestational

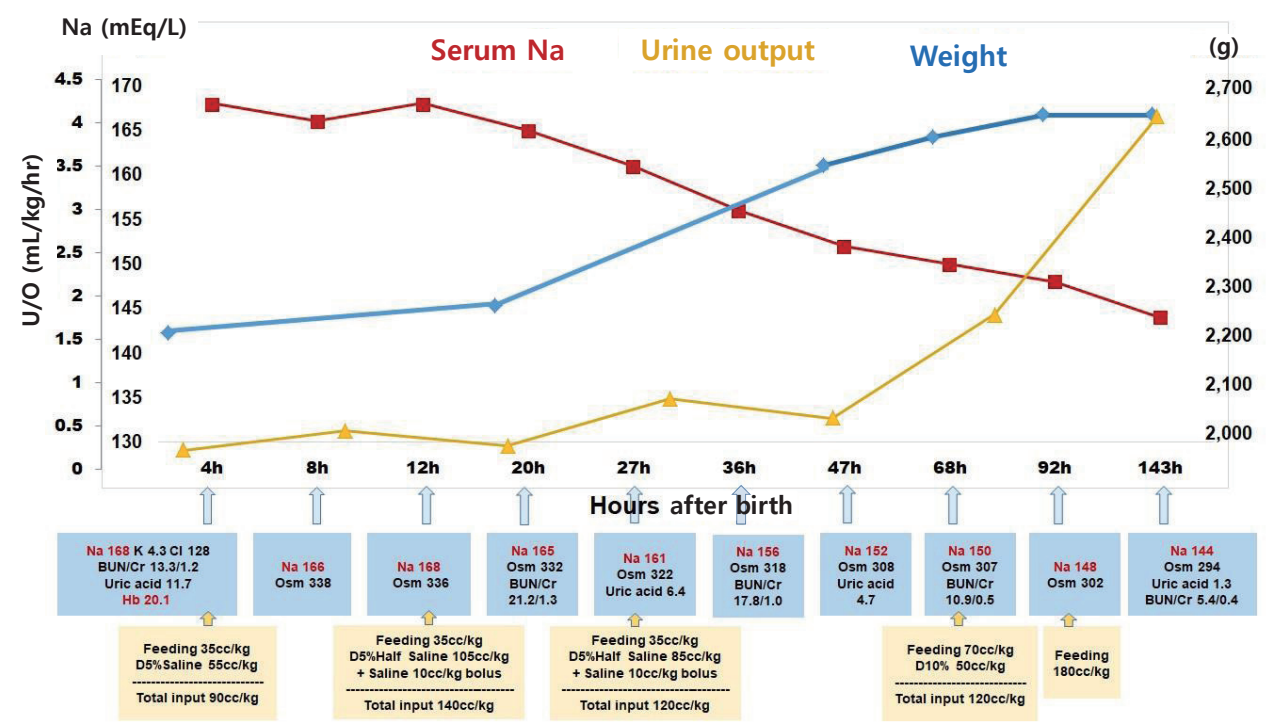

Figure 2. Clinical and laboratory changes after birth. Trophic feeding was started and maintained until 68 hours after birth, and fluid therapies were changed according to calculated free water deficit, plasma sodium level, and urine output. Abbreviations: $\mathrm{Na}$, sodium; U/O, urine output; $\mathrm{K}$, potassium; $\mathrm{Cl}$, chloride; $\mathrm{BUN}$, blood urea nitrogen; $\mathrm{Cr}$, creatinine; $\mathrm{Hb}$, hemoglobin; Osm, osmolality; D5\% saline, normal saline $(0.9 \%)$ with $5 \%$ dextrose; D5\% half saline, $0.45 \%$ normal saline with 5\% dextrose; D10\%, 10\% dextrose. 
DI can occur on rare occasions with elevated placental vasopres sinase, which is often associated with maternal preeclampsia ${ }^{8,9)}$. Gestational DI usually develops in the third trimester and resolves 4 to 6 weeks after delivery, and its diagnosis is difficult ${ }^{8,9)}$. In this case, a decrease in vasopressin, a common complication of trans sphenoidal surgery which might be aggravated by pregnancy, was assumed as a cause of hypernatremia and hyperosmolality in both the mother and fetus ${ }^{10)}$. Desmopressin therapy relieved maternal symptoms.

In summary, neonatal hypernatremia immediately after birth reflects an underlying maternal condition. In this case, uncontrolled maternal central DI was identified as the etiology. The management of neonatal hypernatremic dehydration immediately after birth includes restoring free water deficit, although meticulous fluid therapies that consider time to physiologic diuresis are necessary. This finding implies that conditions similar to DI should be ruled out in mothers with a significantly reduced am niotic fluid volume in the absence of membrane rupture, and proper treatment of maternal DI during pregnancy can aid in avoiding complications.

\section{ARTICLE INFORMATION}

\section{Ethical statement}

Approval for this study was obtained from the Kangwon $\mathrm{Na}$ tional University Hospital Institutional Review Board (IRB No. 2020-04-012). Written informed consent was obtained from the patient's legal guardian.

\section{Conflicts of interest}

No potential conflict of interest relevant to this article was reported.

\section{Author contributions}

Conception or design: E.S.K.

Acquisition, analysis, or interpretation of data: K.L., E.S.K. K.H.C.

Drafting the work or revising: K.L., E.S.K.
Final approval of the manuscript: All authors read and approved the final manuscript.

\section{ORCID}

Kyungmi Lee https://orcid.org/0000-0001-8985-9388

Eun Sun Kim https://orcid.org/0000-0003-1314-150X

\section{Acknowledgments}

None

\section{REFERENCES}

1. Lavagno C, Camozzi P, Renzi S, Lava SA, Simonetti GD, Bian chetti MG, et al. Breastfeeding-associated hypernatremia: a systematic review of the literature. J Hum Lact 2016;32:67-74.

2. Tomarelli G, Arriagada D, Donoso A, Diaz F. Extreme neonatal hypernatremia and acute kidney injury associated with failure of lactation. J Pediatr Intensive Care 2020;9:124-7.

3. Sarin A, Thill A, Yaklin CW. Neonatal hypernatremic dehydration. Pediatr Ann 2019;48:e197-200.

4. Sha XY, Xiong ZF, Liu HS, Di XD, Ma TH. Maternal-fetal fluid balance and aquaporins: from molecule to physiology. Acta Pharmacol Sin 2011;32:716-20.

5. Shennan DB, Boyd CA. Ion transport by the placenta: a review of membrane transport systems. Biochim Biophys Acta 1987;906: 437-57.

6. Schreyer P, Sherman DJ, Ervin MG, Day L, Ross MG. Maternal dehydration: impact on ovine amniotic fluid volume and com. position. J Dev Physiol 1990;13:283-7.

7. Bidiwala KS, Lorenz JM, Kleinman LI. Renal function correlates of postnatal diuresis in preterm infants. Pediatrics 1988;82:50-8.

8. Marques P, Gunawardana K, Grossman A. Transient diabetes insipidus in pregnancy. Endocrinol Diabetes Metab Case Rep 2015;2015:150078.

9. Sum M, Fleischer JB, Khandji AG, Wardlaw SL. Pitfall in the diagnosis of diabetes insipidus and pregnancy. Case Rep Obstet Gynecol 2017;2017:7879038.

10. Lamas C, del Pozo C, Villabona C; Neuroendocrinology Group of the SEEN. Clinical guidelines for management of diabetes insipidus and syndrome of inappropriate antidiuretic hormone secretion after pituitary surgery. Endocrinol Nutr 2014;61:e1524. 